\title{
Perancangan dan Pembuatan Aplikasi Pengenalan Batik "Indonesiaku" Melalui Permainan Berbasis Android
}

\author{
Michael Cornelius Andika \\ Program Studi Teknik Informatika \\ Institut Informatika Indonesia \\ michaelcorneliusandika@yahoo.co.id
}

\author{
Raymond Sutjiadi \\ Program Studi Teknik Informatika \\ Institut Informatika Indonesia \\ raymond@ikado.ac.id
}

\author{
Edwin Meinardi Trianto \\ Program Studi Teknik Informatika \\ Institut Informatika Indonesia \\ edwin@ikado.ac.id
}

\begin{abstract}
Abstrak - Game atau yang biasa disebut permainan merupakan aktivitas terstruktur yang biasanya bertujuan untuk menghibur. Seiring berkembangnya zaman tidak dapat dipungkiri bahwa game terus berkembang pesat. Game itu sendiri telah dipergunakan untuk berbagai macam jenis keperluan, termasuk pendidikan. Jenis konsol yang digunakan juga bervariasi. Di sini penulis mencoba mengembangkan suatu permainan bertema pengenalan budaya batik berjudul "Indonesiaku" dengan tujuan mengenalkan budaya batik di Indonesia yang merupakan warisan budaya bangsa. Permainan ini berbasis Android dan dikembangkan dengan framework Starling serta aplikasi Adobe Flash Builder. Pembuatan batik dalam permainan ini memiliki 4 tahap yaitu nglowong, nembok, medeli, dan nglorod. Tahap tahap tersebut digunakan sebagai simulasi saat membuat batik tulis.

Kata Kunci : game, Android, Batik, Indonesiaku, Adobe Flash Builder
\end{abstract}

\section{PENDAHULUAN}

Dalam era globalisasi ini, perkembangan ilmu pengetahuan dan teknologi semakin maju dan menarik orang dari berbagai kalangan, dari muda maupun tua, dalam mendapatkan informasi. Media buku yang digunakan untuk pembelajaran kini perlahan-lahan ditinggalkan, digantikan dengan media komputer atau smartphone dan internet. Namun, dalam internet yang begitu luas, terkadang informasi mengenai budaya dan sejarah tertinggal karena dinilai kurang menarik. Salah satu nilai budaya Indonesia yang sempat hampir hilang adalah batik. Agar nilai budaya Indonesia tidak dilupakan, inovasi yang tepat dibutuhkan sehingga mempelajari budaya tersebut menjadi menyenangkan dan dapat menarik minat masyarakat. Salah satu cara untuk mendorong tercapainya hal ini adalah dengan memasukkan unsur-unsur kebudayaan batik kedalam salah satu media yang sering digunakan oleh orang-orang.

Media tersebut adalah aplikasi mobile, dalam hal ini adalah aplikasi Android. Karena aplikasi Android sering digunakan sebagai alat dalam pencarian informasi, hampir semua orang menggunakan aplikasi Android untuk memudahkan maupun sebagai hiburan sehari-hari, remaja maupun dewasa.

Aplikasi "Indonesiaku" adalah aplikasi yang bertema casual, history, dan educational. Dalam aplikasi "Indonesiaku" terdapat unsur budaya sehingga pengguna dapat belajar mengenai budaya Indonesia yaitu batik. Didasari latar belakang tersebut, penulis tertarik untuk mendalami pembuatan aplikasi Android dan diwujudkan dengan perancangan dan pembuatan aplikasi pengenalan batik "Indonesiaku" melalui permainan berbasis Android.

\section{METODOLOGI PENELITIAN}

Telah diketahui pada pendahuluan bahwa terdapat beberapa hal yang berperan penting dalam pembuatan aplikasi "Indonesiaku" berbasis Android. Hal-hal tersebut akan dijabarkan pada sub-bab dibawah ini:

\section{A. Batik}

Batik merupakan budaya yang telah lama berkembang dan dikenal oleh masyarakat Indonesia. Pengertian istilah Batik mencakup beberapa rantai nilai yang berawal dari kearifan lokal dan teknologi tradisional hingga industri dan pemasaran modern [1]. Rantai nilai ini mengintegrasikan berbagai hal, mulai dari bahan baku hingga motif. Menghargai batik adalah menghargai rantai-rantai nilai ini seutuhnya.

\section{B. Android}

Android adalah sistem operasi untuk telepon seluler yang berbasis Linux. Android menyediakan platform terbuka bagi para pengembang untuk menciptakan aplikasi mereka sendiri untuk digunakan oleh bermacam piranti bergerak. Android begitu pesat perkembangannya di era saat ini karena Android menyediakan platform terbuka (open source) bagi para pengembang untuk menciptakan aplikasi mereka sendiri.

Perkembangan yang pesat pada sistem Android karena juga didukung oleh hampir keseluruhan vendor smartphone. hal ini karena sifatnya yang open source sehingga siapa saja bisa mengembangkan OS tersebut untuk digunakan pada 
perangkat mereka dan disesuaikan dengan kebutuhan dan pasar. Seperti pada distribusi Linux yang sering berkembang demikian juga dengan Android itu sendiri sejak awal dikembangkan 2009 sampai sekarang sudah memiliki 5 versi dan akan terus berkembang karena pasar yang semakin melirik OS ini dan mudahnya pengembangan.

Android SDK merupakan sebuah tool yang diperlukan untuk mengembangkan aplikasi berbasis Android menggunakan bahasa pemrograman Java [2]. Pada saat ini Android SDK telah menjadi alat bantu dan API (Application Programming Interface) untuk mengembangkan aplikasi bebasis Android. Android SDK dapat dilihat dan unduh pada situs resminya, yaitu http://www.developer.android.com/. Android SDK bersifat gratis dan bebas untuk distribusikan karena Android bersifat open source.

\section{Starling}

Starling adalah ActionScript 3 library untuk Adobe Flash. Starling dapat menggambar tampilan Adobe Flash pada GPU dan memberikan performa yang luar biasa bahkan pada platform mobile, seperti iOS dan Android.

Selain bahasa, Starling tidak memerlukan pengetahuan tentang dasar Flash (ActionScript 3). Starling memulai penjelasan dari awal, dimulai dengan cara mengatur proyek, kemudian menjelaskan bagaimana pohon display dan sistem event bekerja, dan menunjukkan kepada anda bagaimana untuk mencapai tugas-tugas tertentu.

\section{Adobe Flash Builder}

Adobe Flash Builder 4.7 software adalah lingkungan pengembangan untuk membangun game dan aplikasi menggunakan bahasa ActionScript dan kerangka Flex. Adobe Flash Builder membuat aplikasi yang menggunakan infrastruktur Adobe Flex, MXML, Adobe Flash Player, Adobe AIR, ActionScript 3.0, Adobe LiveCycle ES, Layanan Data Komponen, dan Adobe Flex Charting. Adobe Flash Builder juga termasuk alat untuk pengujian, debugging, dan profiling, yang dicapai melalui peningkatan produktivitas dan efisiensi.

\section{HASIL PEMBAHASAN}

Agar pengembangan aplikasi lebih maksimal, melakukan analisa terhadap aplikasi sangat penting, sehingga sistem yang akan dibangun memiliki acuan dan gambaran umum.

\section{A. Use Case Diagram}

Use case diagram adalah diagram yang bertujuan untuk menunjukkan interaksi yang terjadi antara aktor eksternal dan sistem yang digunakan. Use case diagram juga serta mempresentasikan interaksi antar aktor/pelaku dengan sistem. Untuk gambaran lebih jelas dapat dilihat pada gambar use case diagram di gambar 1 .

Dari use case diagram tersebut, dapat dilihat interaksi yang terjadi dalam permainan "Nusantara Indonesia", antara lain pilih lokasi, ubah pengaturan, keluar permainan, dan lihat skor.

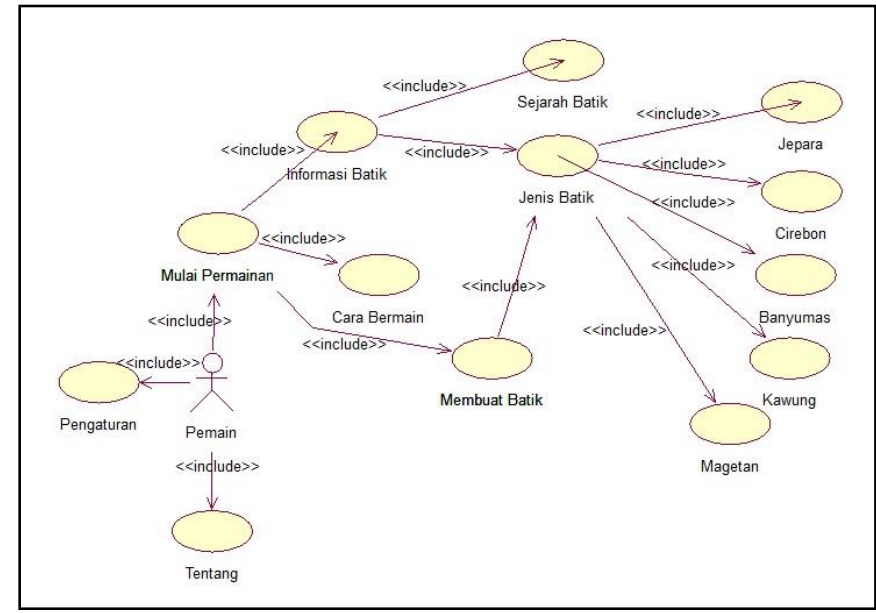

Gambar 1. Use Case Diagram Permainan.

\section{B. Activity Diagram}

Activity diagram adalah gambaran object-oriented dari flow chart dan data flow diagram dalam suatu pengembangan struktur sistem [3]. Activity diagram menggambarkan alur kerja dan perilaku sistem, menggambarkan kontrol sistem dari satu aktivitas ke aktivitas lain, menunjukkan use case yang ada didalam sistem, dan memberikan tampilan rinci mengenai proses aplikasi tersebut. Berikut adalah activity-activity diagram dari aplikasi ini:

a) Activity Diagram Indonesiaku

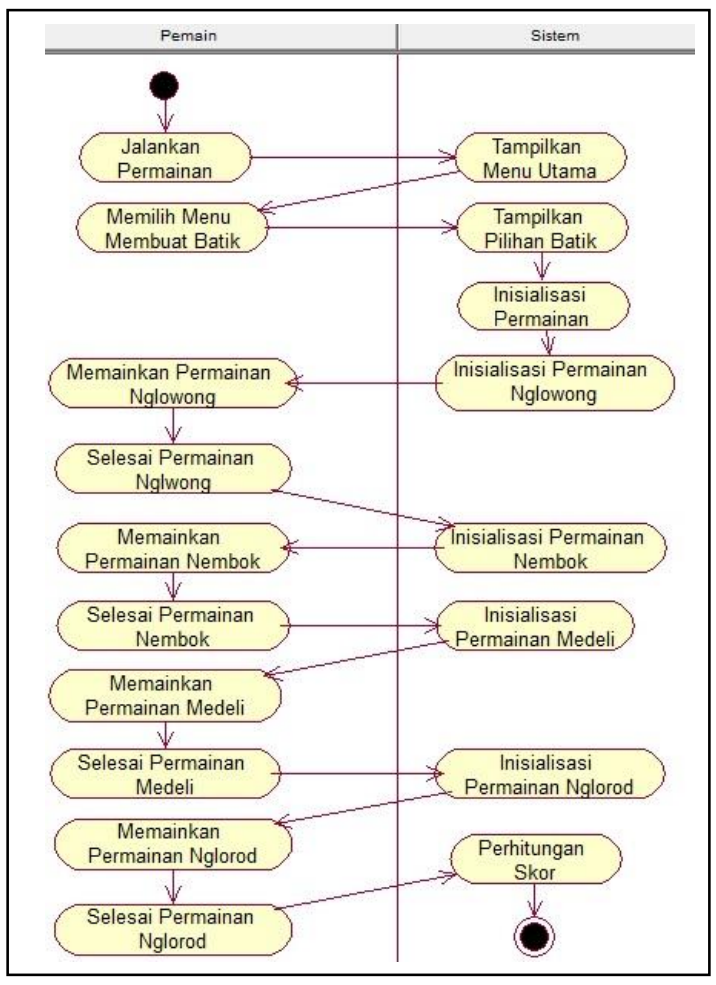

Gambar 2. Activity Diagram Indonesiaku.

b) Activity Diagram Nglowong 


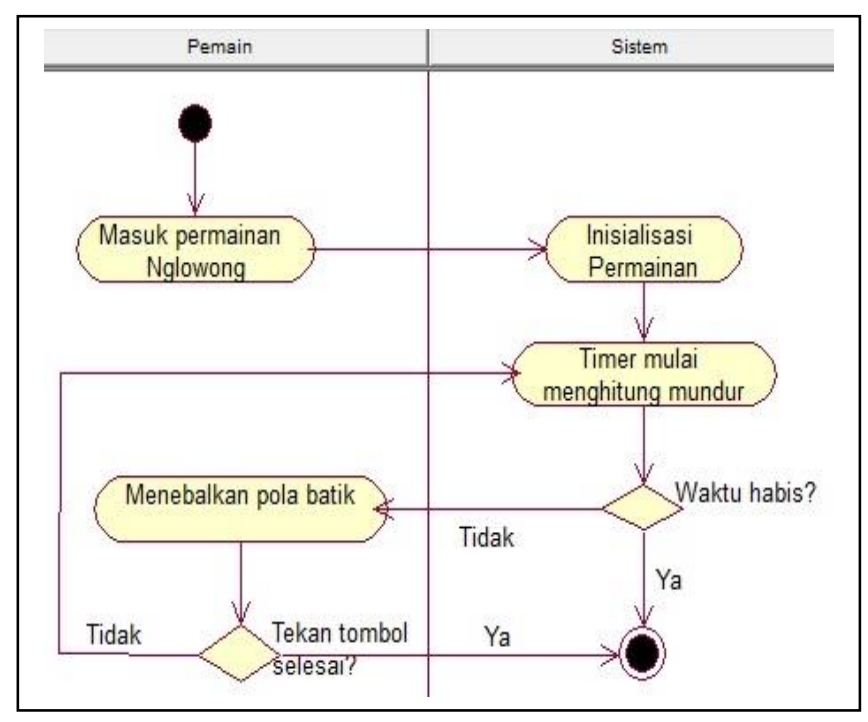

Gambar 3. Activity Diagram Nglowong.

c) Activity Diagram Nembok

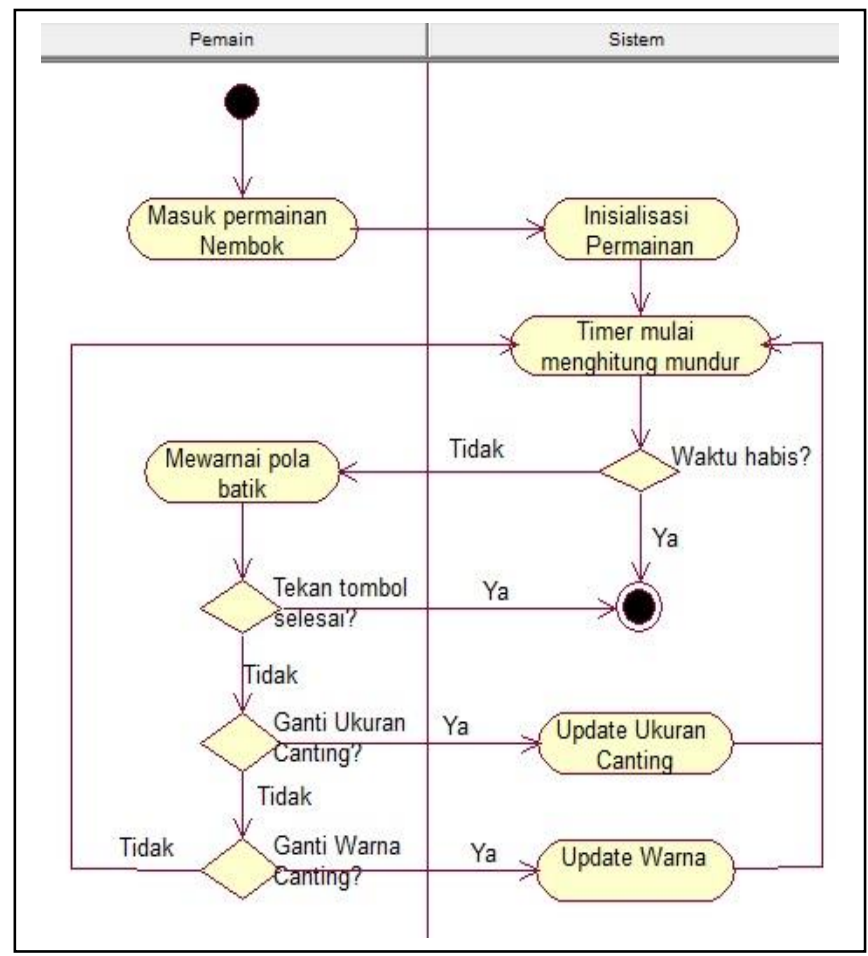

Gambar 4. Activity Diagram Nembok.

d) Activity Diagram Medeli

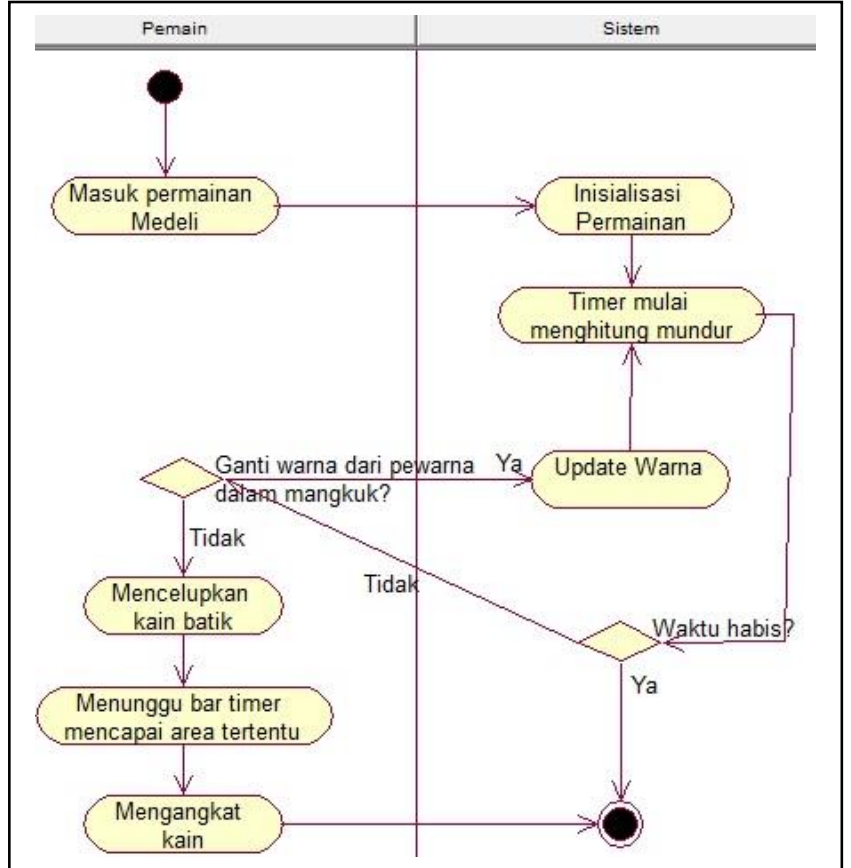

Gambar 5. Activity Diagram Medeli.

e) Activity Diagram Nglorod

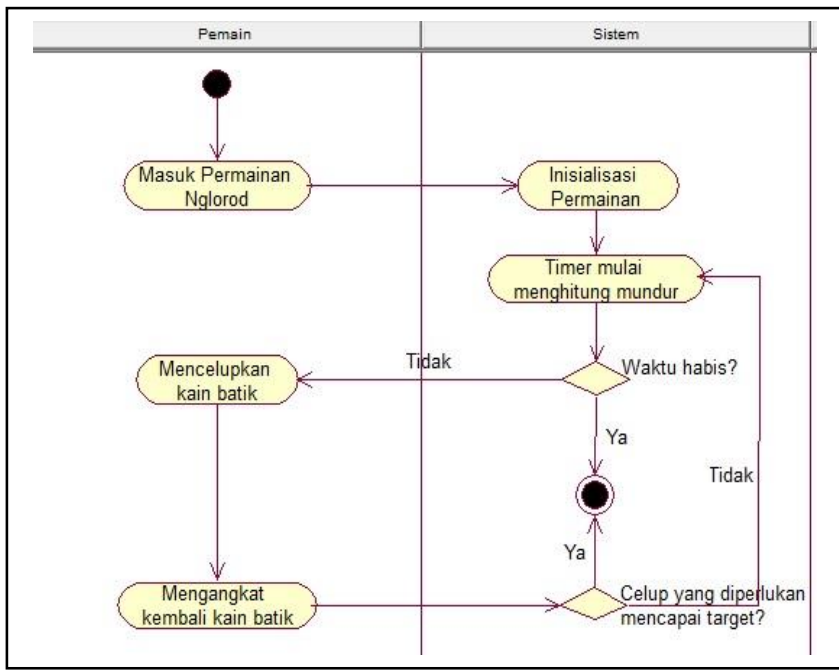

Gambar 6. Activity Diagram Nglorod.

C. User Interface

Pada sub bab ini akan ditunjukkan tampilan antar muka dari permainan "Indonesiaku" yang nantinya akan berinteraksi dengan user.

- Menu Utama

Menu Utama adalah menu awal dari permainan ini. Di dalam menu ini terdapat 5 buah tombol yaitu tombol Mulai, Skor Tertinggi, Tentang, dan Pengaturan yang mengarah ke menu lainnya, serta tombol keluar untuk keluar dari permainan. 


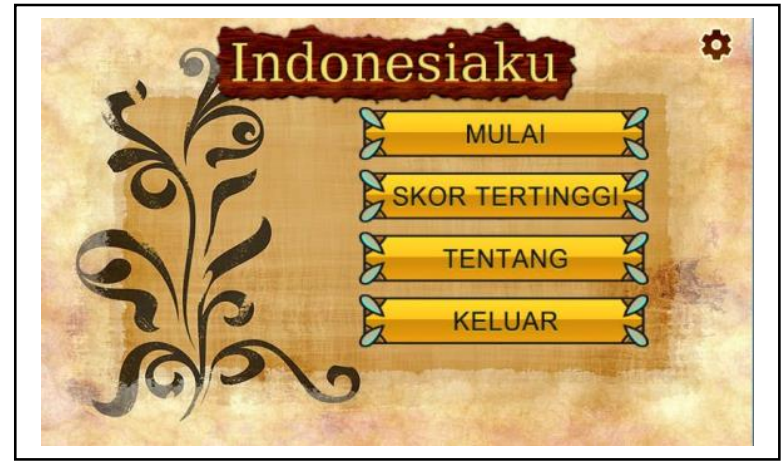

Gambar 7. Menu Utama.

- Menu Permainan

Menu Permainan berisikan pilihan yang berhubungan dengan permainan, diantaranya yaitu tombol informasi batik, tutorial, membuat batik, dan tombol kembali.

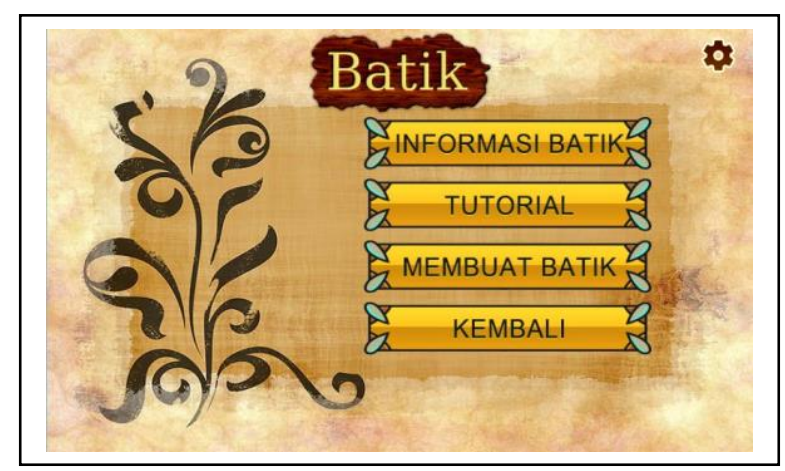

Gambar 8. Menu Permainan.

- Halaman Informasi Menu

Halaman Informasi Menu berisi menu tentang batik yang ingin ditampilkan yaitu jenis batik dan sejarah batik.

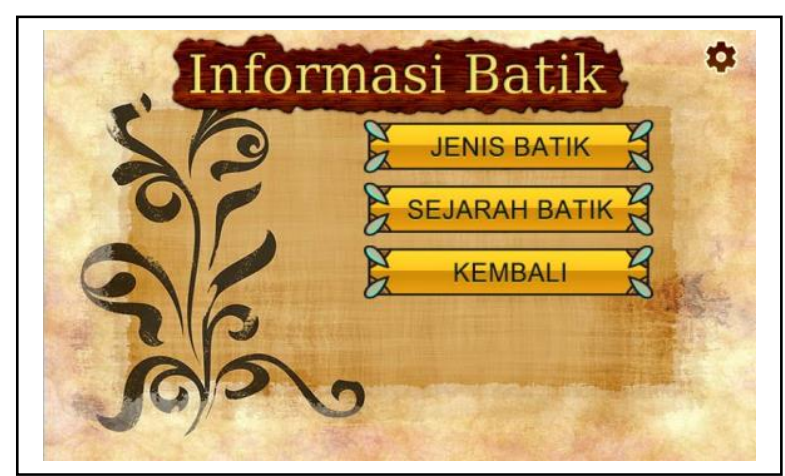

Gambar 9. Halaman Informasi Menu.

- Halaman Jenis Batik

Halaman ini memberikan pilihan jenis batik yang ingin ditampilkan informasinya. Pada saat user telah memilih batik yang ingin ditampilkan informasinya maka tombol lanjut di kanan bawah akan menjadi aktif.

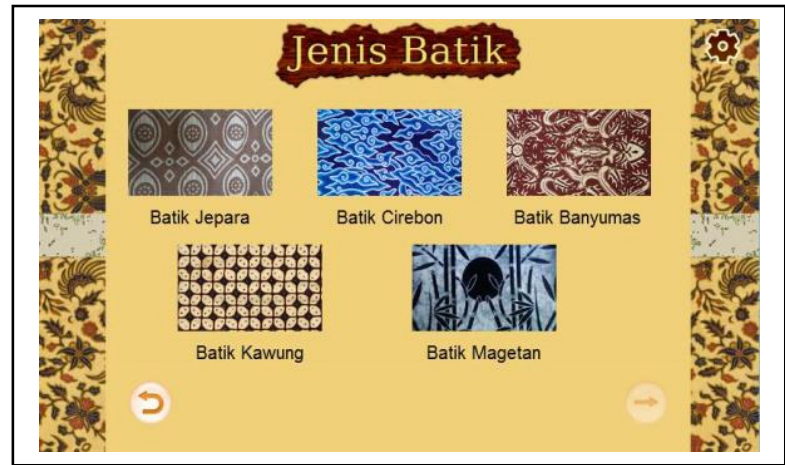

Gambar 10. Halaman Jenis Batik.

- Halaman Informasi Batik

Halaman ini menampilkan informasi mengenai natik yang dipilih, di sisi kiri bawah terdapat tombol untuk kembali ke menu sebelumnya, selain itu di sisi tengah kanan dan tengah kiri terdapat tombol untuk lanjut ke halaman berikutnya atau halaman sebelumnya..

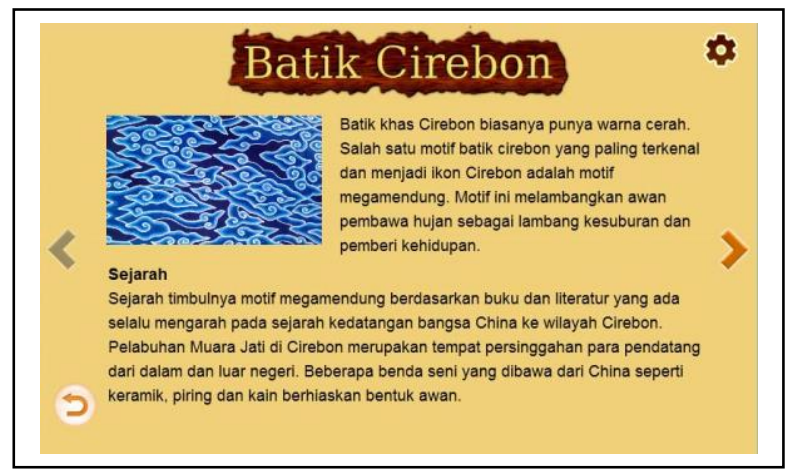

Gambar 11. Halaman Informasi Batik.

- Menu Sejarah Batik

Halaman ini menampilkan mengenai sejarah batik. Di sisi kiri bawah terdapat tombol untuk kembali ke menu sebelumnya. sisi tengah kanan dan tengah kiri terdapat tombol untuk lanjut ke halaman berikutnya atau halaman sebelumnya.

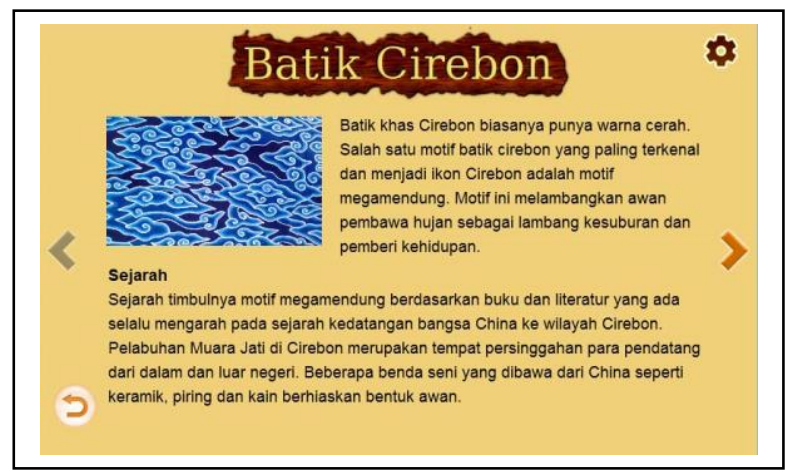

Gambar 12. Menu Sejarah Batik.

- Halaman Tutorial 
Halaman ini menampilkan informasi mengenai tutorial cara bermain saat membuat batik setiap tahapnya. Pemain juga dapat melakukan swipe untuk mengganti halaman.

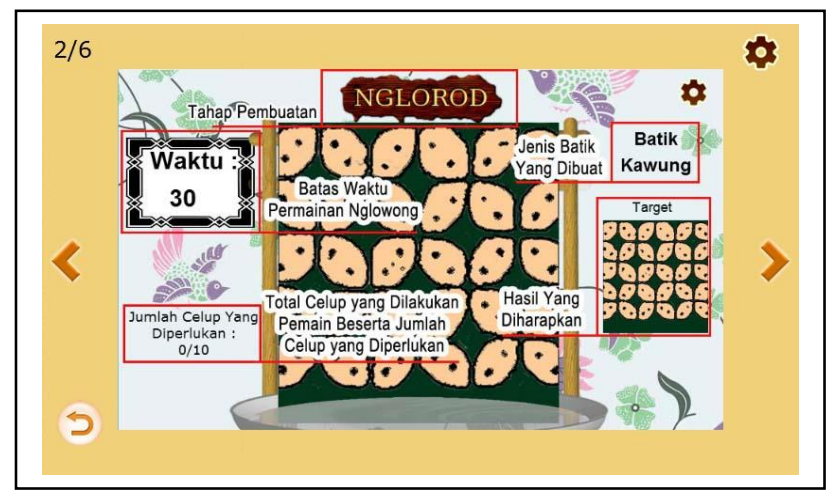

Gambar 13. Menu Tutorial.

- Menu Permainan Nglowong

Pada permainan Nglowong, pemain harus menebalkan pola sebelum waktu habis sebelum melanjutkan ke tahap berikutnya. Pemain menggunakan fitur touch and drag untuk menebalkan pola.

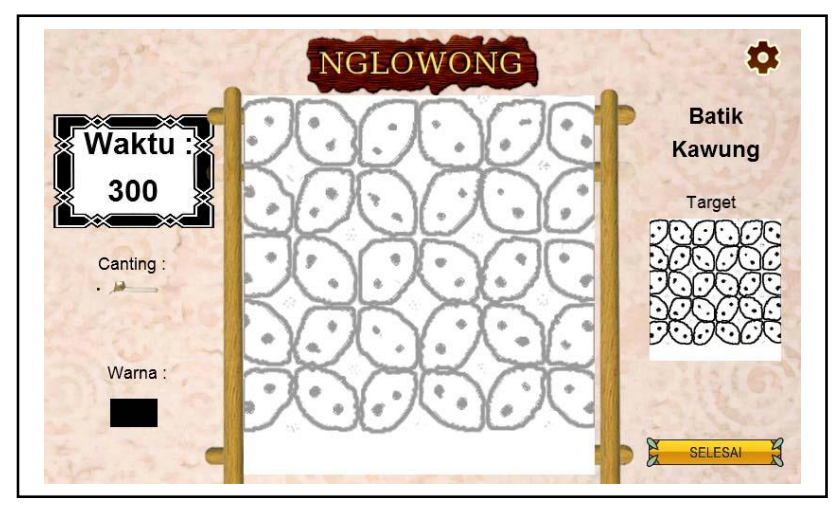

Gambar 14. Menu Permainan Nglowong.

- Menu Permainan Nembok

Pada menu permainan Nembok, pemain harus mewarnai bagian dalam pola sebelum waktu habis untuk dapat melanjutkan tahap berikutnya. Pemain dapat memilih warna dan mengganti ukuran canting pada tahap ini. Pemain menggunakan fitur touch and drag untuk mewarnai pola.

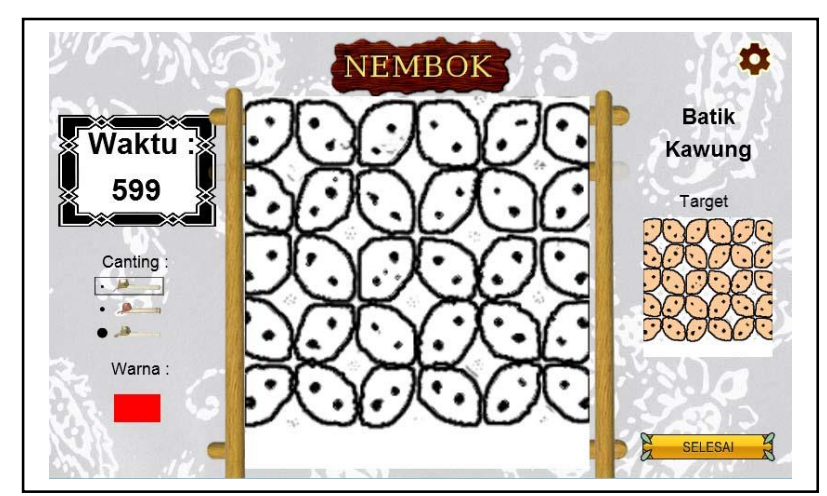

Gambar 15. Menu Permainan Nembok.

- Menu Permainan Medeli

Pada menu permainan medeli, pemain diminta memilih warna yang sesuai dengan target kemudian mencelupkan kain ke dalam pewarna dengan menggunakan drag. Setelah dicelupkan maka akan muncul bar timer yang digunakan sebagai indikator lama pencelupan. Pemain kemuduan diminta mengangkat kain tersebut dari pewarna menggunakan tombol angkat.

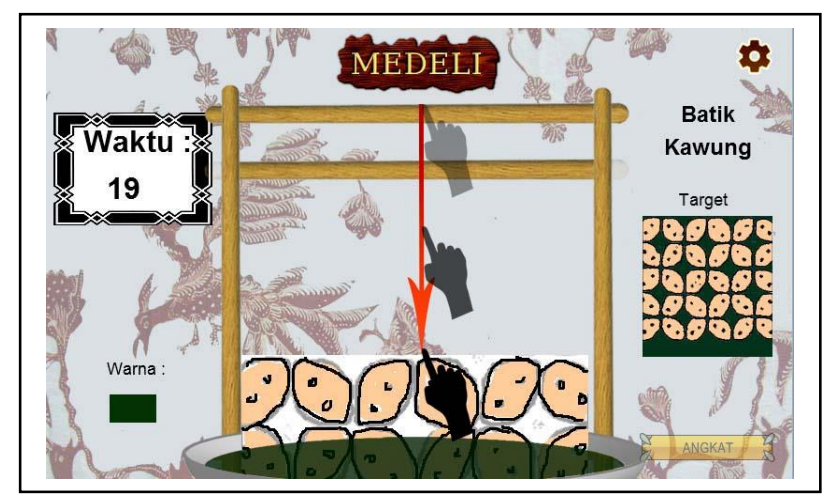

Gambar 16. Menu Permaianan Medeli.

- Menu Permainan Nglorod

Pada menu permainan nglorod pemain diminta untuk mencelupkan kain ke dalam air panas secara berulangulang hingga mencapai jumlah celup yang diperlukan, sebelum waktu yang diberikan habis.

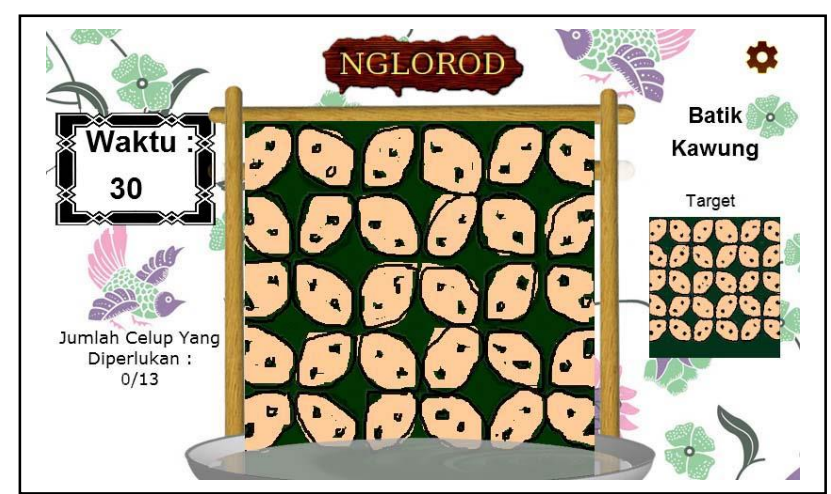


Gambar 17. Menu Permainan Nglorod.

- Skor Pemain

Pada saat pemain telah menyelesaikan ke empat tahapan dalam pembuatan batik, maka skor akhir permainan akan muncul. Pada halaman skor tersebut terdapat pilihan pilih batik untuk bermain lagi menggunakan motif berbeda, dan tombol menu utama.

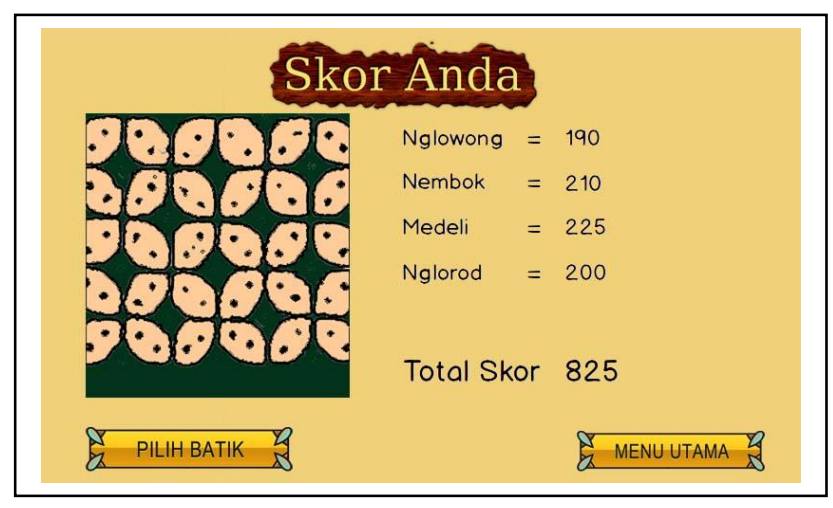

Gambar 18. Skor Pemain.

\section{Pengujian}

Aplikasi permainan "Indonesiaku" diuji dengan dua skenario, yaitu pengujian fungsional dan pengujian terhadap pengguna. Pengujian fungsional dilakukan dengan metode black box testing menggunakan pengetesan state transition. Aspek-aspek yang diuji pada pengujian ini meliputi pengujian fungsionalitas pada tiap permainan, pengujian kesalahan, pengujian antarmuka, dan pengujian kasus penggunaan.

Untuk pengujian fungsional, semua skenario pengujian yang dilakukan memberikan hasil yang baik. Hal ini menunjukkan bahwa secara fungsionalitas aplikasi ini telah berjalan seperti yang diharapkan.

Pengujian selanjutnya dilakukan kepada pengguna yang telah memainkan permainan "Indonesiaku" hingga akhir pada perangkat Android. Responden berjumlah 30 orang dengan range umur 12-40 tahun. Kuesioner yang diberikan meliputi 6 penilaian, yaitu Attractiveness (daya tarik), Perspicuity (kemudahan untuk menggunakan aplikasi), Efficiency (efisiensi), Dependability (interaksi kontrol yang dirasakan), Stimulation (kesenangan dan motivasi saat menggunakan aplikasi), Novelty (inovasi dan kreatif). Tabel 1 menunjukkan perbandingan hasil uji coba menggunakan UEQ.

Tabel 1. Hasil Uji Coba Menggunakan UEQ.

\begin{tabular}{|l|cl|} 
Scale & Mean & Comparisson to benchmark \\
\hline Attractiveness & 0,622222222 & Bad \\
\hline Perspicuity & 0,783333333 & Below Average \\
\hline Efficiency & 0,416666667 & Bad \\
\hline Dependability & 0,708333333 & Bad \\
\hline Stimulation & 0,575 & Below Average \\
\hline Novelty & 0,141666667 & Bad \\
\hline
\end{tabular}

\section{KESIMPULAN DAN SARAN}

Pada bab ini diberikan beberapa kesimpulan yang dapat diambil dari uji coba yang sebelumnya telah dilakukan. Selain itu juga diberikan saran-saran yang bermanfaat dan membangun untuk pengembangan sistem lebih lanjut.

A. Kesimpulan

Hasil dari penelitian ini dapat disimpulkan sebagai berikut:

1) Perancangan dan pembuatan aplikasi berbasis Android dapat dibuat dengan berbagai tools. Pada penelitian ini tools yang digunakan adalah Adobe Flash Builder dan framework Starling.

2) Pada rancangan awal terdapat 3 aspek yang dibuat yaitu menampilkan sejarah batik, cara pembuatan, dan simulasi pembuatan batik yang disajikan dalam bentuk permainan. Dengan adanya 4 tahap permainan saat pembuatan batik, permainan "Indonesiaku" menjadi cukup menarik. Hal ini didukung oleh hasil kuesioner yang menyatakan permainan dinilai menarik oleh $90 \%$ responden. Walaupun nilai keseluruhan daya tarik (Attractiveness) dari permainan dinilai kurang baik.

3) Dengan adanya aplikasi "Indonesiaku" kurang dapat membantu masyarakat untuk memperkenalkan budaya batik. Hal ini dibuktikan dengan nilai stimulation yang masih di bawah rata-rata.

B. Saran

Saran yang diterima untuk pengembangan lebih lanjut Permainan "Indonesiaku" adalah:

1) Penyesuaian permainan dengan ukuran resolusi layar agar lebih kompatibel dan tidak mengganggu gameplay dari permainan.

2) Tutorial permainan lebih baik dibuat lebih interactive dan merupakan step-by-step tutorial.

3) Dapat ditambahkan transisi pada perpindahan layar permainan.

4) Permainan batik yang digunakan lebih bervariatif dan dibuat agar lebih menarik untuk dimainkan.

5) Penambahan pilihan jenis batik yang ada di Indonesia, tidak terbatas pada 5 batik yang telah ada.

\section{REFERENSI}

[1] Gratha, B. (2012). Panduan Mudah Belajar Membatik. Jakarta: Demedia Pustaka.

[2] Safaat H, N. (2012). Pemrograman Aplikasi Mobile Smartphone dan Tablet PC Berbasis Android, Edisi Revisi, Bandung: Informatika.

[3] Mala, D. J., (2013). Object Oriented Analysis and Design Using UML. USA: Tata McGraw Hill Education. 